\title{
Analysis of Teachers' Role as Emotional Guide under Flipped Classroom Teaching Context
}

\author{
Huanhuan Ren ${ }^{1, a^{*}}$ and Chi Ma ${ }^{2, b}$ \\ ${ }^{1}$ Teaching and Research Institute of Foreign Languages, Bohai University, Jinzhou 121013, China \\ 2 Jinzhou Institute of Forestry Research, Jinzhou Forestry Bureau, Jinzhou 121013, China \\ arenhuanhuan2014@163.com, ${ }^{b}$ machi2014@tom.com
}

Keywords: Teachers' Role; Emotional Guide; Flipped Classroom Teaching Context

\begin{abstract}
Emotions affect students' developments from many aspects, and emotional education is an indivisible part of whole education. This research looks at teachers' role as emotional guide under flipped classroom teaching context. Grounded in holistic review of emotional education and significance analysis of teacher emotion guide, we offer solutions for teachers to optimize academic outcomes and emotional intelligence. Our proposition is that teachers' role as emotional guide under flipped classroom teaching context may be carried out on two planes, guide for avoiding negative emotions of learners and guide for generating positive emotions of learners. It's predicted that teachers' role as emotional guide should sustain positive learning outcomes and foster emotional attainments within flipped classroom teaching mode.
\end{abstract}

\section{Introduction}

Emotional education is an indivisible part of whole education. Cognitive factors should not function independently or exclusively without the participation of affective factors in any educational settings. The paramount duty teachers need to work on is to offer emotional guidance for learners under flipped classroom teaching context so as to maximize academic outcomes even while fostering emotional intelligence and innovation. In this regard, we investigates and examines the contribution of teachers' role as emotional guide under flipped classroom teaching context. This article is a summary of this research work, hopefully providing theoretical support and guidance for instructors who are going for a flipped classroom in future practice.

\section{Holistic Review of Emotional Education and Emotional Guide}

The Rise of Emotional Education. Various perspectives of emotions can be offered in an attempt to characterize meaning of emotions including cognitive view, psychological view and philosophical view[1-3]. It's concluded that emotions are complex phenomena and rich in content, and the main characteristics of emotions are richness, heterogeneity, vagueness and openness for multiple interpretations[4]. Obvious benefits of emotions are found in many aspects in a person' life. Benefits of emotions are not limited to raising cognitive level of learners, but also promoting other qualities of individuals[5]. According to the researches of Daniel Goleman, professor of psychology at Harvard University, intelligence quotient contributes only about $20 \%$ to success in life, the rest $80 \%$ of success depends on emotional intelligence[6]. It's concurred that affective competence plays a decisive role in personal success at work, personal mental health, happy life and so forth[7]. Furthermore, it's made evident that emotional education is part of school education, which focuses on students' attitude, emotions, feelings and beliefs, and students' individual development and social development as well as their self-esteem should be included in emotional education[8].

Teachers' Role as Emotional Guide. Since the cultivation of emotional intelligence is not supposed to be underestimated, instructors should pay special attention to various emotions of learners. How to take good care of learners' emotions? Instructors are encouraged to assist learners in guiding them toward emotional intelligence and attainments? It's suggested that language educators should keep 
a watchful eye on the two forms of operating patterns of affective factors taking place in language pedagogy, which are emotions affecting learning and affecting emotions in learning[9]. In other words, learner emotions, on one hand, are regarded as a tool of teaching to promote students' cognitive competencies, and on the other hand, as an objective of teaching to promote students' emotional competencies[10]. Emphasis of instructors should be placed on combining the two aspects together and engaging affective factors into specific teaching approaches, ultimately to promote students' cognitive and emotional attainments[11]. Given the role of teacher emotional guide is intended to be into full play, emotional achievement of learners can be guaranteed.

\section{Significance of Teacher Emotion Guide under Flipped Classroom Teaching Context}

Emotions under Flipped Classroom Teaching Context. Flipped classroom is a relatively new concept which gained traction in the latter part of the last decade and it is already being embraced to a certain extent by scholars in universities and schools[12]. Instructors who are flipping their class often feel the impact of this shift, with flipped classroom inverting traditional teaching methods through delivering instruction online outside of class and moving homework into the classroom[13]. Especially, recent advances in technology have unlocked entirely new possibilities for flipped classroom in most fields. New development pattern under the background of modern science and technology innovation may occur[14]. In this regard, the choices learners make in language learning involve both mental and emotional processing, and particular learner emotions under flipped classroom teaching context are highly affected by many factors. It's true that learners who have trouble managing their emotional health are prone to develop a number of cognitive problems in learning field.

Needs for Teacher Emotional Guide from Learners. It's concurred that flipping the classroom means learners have to completely re-think how to do the learning job they have done a certain way for years. More importantly, it's quite possible that those who haven't undergone a successful transition under flipped classroom teaching context may suffer from frustration and even desperation. Over time, any underestimate of emotions of learners throughout the flipped classroom teaching process will ultimately lead to 'emotional illiteracy', 'emotional deficiency' and even 'emotional hunger'. In the meanwhile, cognitive reasoning may be influenced by the way the learner feel about a certain situation[15]. In other words, without the participation of affective processes in learning, the effectiveness of cognitive acquisition in flipped classroom teaching mode is not guaranteed. Therefore, how to keep learners emotional healthy through providing emotional guide has become a compelling and demanding work for any instructor under flipped classroom teaching context.

\section{Analysis of Teachers' Role as Emotional Guide under Flipped Classroom Teaching Context}

The Guide for Generating Positive Emotions of Learners. American educational psychologist Benjamin S. Bloom and other scholars regard affective competence as one of the three educational objectives, and further stress that affective objectives typically target the awareness and growth in attitudes, emotion, and feelings of learners[16]. Given the role of emotions played in determining learning outcomes under flipped classroom teaching context, the move of generating positive emotions of learners is critical and essential. In the first place, instructors ought to evoke learners' inner interest in learning as opposed to involving learners without their emotional engagement, as behavioral engagement takes place within an emotional atmosphere may lead to better attainments. For example, instructors may provide rationales to explain the lesson's utility, importance, meaning and hidden value, justifie students' investment of effort, motivate students on uninteresting but important lessons, in hope that interest in learning may help learners in a better position in personal developemnt under flipped classroom teaching context. What's more, through designing and providing hand-on tasks and activities, instructors should make sure that learners enjoy a joyful and fruitfull learning expeirence rather than a stressfull and boring one. In this process, loose assessment should also be incorporated into flipped classroom so that learners can take risks and develop confidence. Besides, activities that emphasize social interaction and that engage the entire body tend to provide the most emotional support. Emotional 
education transcends individual students and emphasizes the relationship among students, and interpersonal and social skills are the core of emotional education[17]. Under the flipped classroom model, rich contact between students and teacher increases as learners keeps more in touch with instructors and peer students for exploratory questions and timely feedback outside school day[18]. In this respect, group works and cooperative opportunities should be designed in the flipped classroom teaching mode. It's believed that leveraging our own and others' emotions is good for carrying out more responsibilities and reaching high aspirations[19]. It's made evident that the people best able to obtain desired attainments are the ones who can regulate their emotions for better use.

The Guide for Avoiding Negative Emotions of Learners. There are many good reasons for avoiding negative emotions of learners through teachers constantly providing effective guidance under flipped classroom teaching context. One issue that deserves more consideration and concern is how to offer guide for avoiding negative emotions of learners whist teachers flipping classroom. It's suggested that the action plan of guiding learners against negative emotions should be denoted in four dimensions. Above all, instructors are encouraged to respect and acknowledge negative emotions from learners considering emotions are no more than valid reactions to the teacher's constraints, demands, and imposed structures. One thing that we can't ignore is, although reason may override our emotions, it rarely changes our real feelings about an issue. That's why it's argued that emotion is often a more powerful determinant of our behavior than our brain's rational processes[20]. Teachers are not supposed to counter students' negative affect, arguing that such attitude is unacceptable- something that needs to be changed, fixed, or reversed into a more acceptance attitude. Instead, negative emotions of learners should be interpreted and explained by instructors as as to elicit a possible and effcient solution which may help learnes' emotional problems. With less energy devoted to controlling one's emotions, there's more to put towards the things through which instructors may know where emotions are from. Sometimes, teachers have hard time figuring out the real inner world of the learner. Hence, besides taking dynamic notice of emotions, instructors should invlove learners in talking about their emotions and listening to those of others[21]. Those dialogues and interaction assist learners in maintaining a clear and focused mind of their emotions, and enable instructors to make judgments about when emotions of learners are interfering with or supporting learning[22]. What's more, it's advisable that learners be assisted in getting ride of negative emotions and going for a positve learning experience through personalized and invividualized action plans by teachers. It's hoped that students can make their emotions work for them and not against them. Last but not the least, instructors seek to monitor and observe emotions of learners for a look at whether bad emotions are in a good control of learners. If possible, some tailored feedback and suggestion should be delivered to learners for future action pertinent to emotional improvment. With more patience and efforts, instructors can pick learners up form where they tripped over under flipped classroom teaching context.

\section{Epilogue}

It's observed that emotions affect students' developments from many aspects. This research looks at teachers' role as emotional guide under flipped classroom teaching context. Grounded in holistic review of emotional education and significance analysis of teacher emotion guide, we offer solutions for teachers to optimize academic outcomes and emotional intelligence. Our proposition is that teachers' role as emotional guide under flipped classroom teaching context may be carried out on two planes, guide for avoiding negative emotions of learners and guide for generating positive emotions of learners. It's predicted that teachers' role as emotional guide should sustain positive learning outcomes and foster emotional attainments under flipped classroom teaching context.

\section{Acknowledgements}

This work is part of the project of Research on Teacher Autonomy Support and Teacher Emotional Guide under College English Flipped Classroom Teaching Context, the project of On Cultivating and 
Developing Liaoning Scientific Foreign Language Talents with View to Bourdieu' Theory, the project of On Establishing Generative Mechanism of EFL Autonomous Learning Behaviors and Strengthening Development of Learning Field in Ubiquitous Learning Space, and the project of On Constructing Mechanism and Strategies for College English Autonomous Learning Abilities via Mobile Multimedia. This research was supported by the fund of Bohai University Teaching Reform Research (Project No. BDJG2016QC09), the fund of Liaoning Planning of Philosophy and Social Science (Project No. L16CYY001), the fund of Liaoning Provincial Federation Social Science Circles (Project No. 2017lslktyb-019), and the fund of the Thirteenth Five-Year Plan of Education Sciences of Liaoning Province (Project No. JG16DB013).

\section{References}

[1] J. Russell, "Core affect and the psychological construction of emotion," Psychological Review, vol. 110, pp. 145-172, 2003.

[2] Z.-X. Zhu, The Dictionary of Industrial Psychology, Beijing: Beijing Normal University Press, 1989.

[3][4][5][15] H.-H. Ren, C. Ma. The Operating Patterns of Learner Emotions in Second Language Learning. In C. Li (ed.). Advances in Intelligent Systems Research V105. France: Atlantis Press. May 22-23, 2015, pp. 601-603.

[6] [7] D. Goleman, Emotional Intelligence, Shanghai: Shanghai Scientific and Technical Publishers, 1997.

[8] [17] P. Lang, “Affective education - an international perspective," Journal of East China Normal University (Educational Sciences), vol. 3, pp. 25-36, 1995.

[9][10][11] H.-H. Ren. Educational Values and Developing Paths of Emotional Education in English Courses. Journal of Education Development. 2016. (5):44-48.

[12][13][14] H.-H. Ren, C. Ma. On Exploring Flipped Classroom Teaching Mode Based on the Development of Information Technology. In J. Wang, N. Xin and H. Y. Zhou (eds.). Advances in Computer Science Research v 59. Paris: Atlantis Press. December 2016, pp.1337-1341.

[16] D. R. Krathwohl, B. S. Bloom and B.B. Masia, Taxonomy of Educational Objectives: Affective Domain, David McKay Company, Inc, 1964.

[18][19] H.-H. Ren, C. Ma. On Exploring Flipped Classroom Teaching Mode Based on the Development of Information Technology. In J. Wang, N. Xin and H. Y. Zhou (eds.). Advances in Computer Science Research v 59. Paris: Atlantis Press. December 2016, pp.1337-1341.

[20] S. Robert. How emotions affect learning. Educational leadership, 1994 (52):60-65.

[21][22] H.-H. Ren, C. Ma. On resolving emotional differentiation of language learners in college English layering teaching system. Advances in Social Science, Education and Humanities Research V 85. Paris: Atlantis Press. October 2016, pp.910-915. 